\title{
Sister Marie-Joseph's Nodule in an Ovarian Adenocarcinoma: A Case Report
}

\author{
Aboutarik Fatima Ezzahra $^{1 *}$, Rizkou Jihane ${ }^{1}$, Roudi Safae ${ }^{1}$, Ait Errami Adil ${ }^{1}$, Samlani Zouhour ${ }^{1}$, Krati Khadija ${ }^{1}$, Oubaha
} Sofia $^{2}$

${ }^{1}$ Departement of Hepato-gastro-enterology, Arrazihospital, Mohammed VI universityhospital Center, Marrakech 40000, Morocco
${ }^{2}$ Departement of Physiology, Faculty of Medicine, Cadi Ayyaduniversity, Marrakech 40000, Morocco

DOI: $10.36347 /$ sjams.2020.v08i07.026

| Received: 12.07.2020 | Accepted: 20.07.2020 | Published: 24.07.2020

*Corresponding author: Aboutarik Fatima Ezzahra

Sister Mary Joseph's nodule (SMJN) is a metastatic umbilical tumor. It is a very rare condition, with a poor prognosis; however, it can be the first sign of intra-abdominal cancer, most commonly an adenocarcinoma metastasis from a gastrointestinal or gynecologic primary malignancy. We report a case of umbilical skin metastasis (or Sister MarieJoseph's nodule) revealing bilateral ovarian adenocarcinoma in a 61-year-old patient. And through this case we emphasize on the delayed diagnosis associated with this tumor.

Keywords: Sister Mary Joseph's nodule (SMJN), Umbilical metastasis-Ovarian adenocarcinoma, Palliative chemotherapy.

Copyright @ 2020: This is an open-access article distributed under the terms of the Creative Commons Attribution license which permits unrestricted use, distribution, and reproduction in any medium for non-commercial use (NonCommercial, or CC-BY-NC) provided the original author and source are credited.

\section{INTRODUCTION}

Sister Marie-Joseph's nodule is an exceptional metastatic localization of a cancer, most often an intraabdominal and/or a pelvic one. It is a discreet and rare clinical sign, which not only shows the occurrence of a visceral malignant tumor but also the poor prognosis of this tumor [1, 2]. It has a problem of etiological diagnosis because the search for the primary tumor is not always easy. The aim of our work is to highlight the delayed diagnosis, and to emphasize the importance of correctly diagnosing an umbilical nodule in order to avoid this delay.

\section{Case Report}

We report the case of a 61-year-old patient, with no significant personal or family history, admitted for a painful umbilical swelling that appeared 3 months prior, associated with diffuse abdominal distension without any notion of transit disorder. Physical examination revealed an ascites of medium abundance, with a $4 \mathrm{~cm}$ ulcerated, oozing, and painful umbilical nodule (Figure 1). The cervix and vaginal walls were macroscopically normal.

The cytology of ascites fluid objectified the presence of tumor cells. Laboratory investigation showed increased serum CA 125 levels of $800 \mathrm{ng} / \mathrm{ml}$ $(\mathrm{N}<5 \mathrm{ng} / \mathrm{ml})$. The abdominopelvic CT scan revealed two bilateral ovarian masses: the right one measure $48^{*}$ $39 \mathrm{~mm}$ and the left $48^{*} 34 \mathrm{~mm}$, with a cystic and fleshy component and left tubal extension. The CT scan also revealed a peritoneal effusion of medium abundance, associated with peritoneal carcinosis nodules. AKrukenbergsyndrom was suspected and an oesogastro-duodenal fibroscopywas performed, however it didn't show anygastric lesion. Histological and immunohistochemical examination of the umbilical mass biopsy was in favor of umbilical metastasis of an ovarian adenocarcinoma. This diagnosis with umbilical and peritoneal metastasis was retained, and the therapeutic approach was a palliative chemotherapy. However, the patient died two months later. 


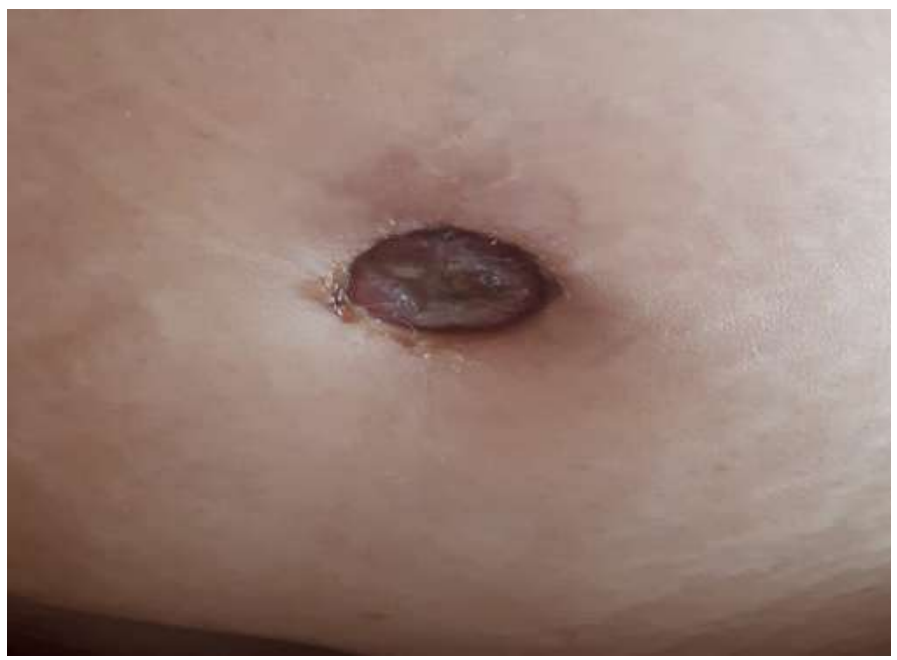

Fig-1: clinical aspect of Sister Marie-Joseph's nodule

\section{DISCUSSION}

Sister Mary Joseph's nodule (SMJ) is a palpable cutaneous umbilical nodule, most often secondary to a metastasis from an abdomino-pelvic malignancy. Classically, the primary tumor is an adenocarcinoma in $75 \%$, most commonly of gastric, ovarian, colonic or pancreatic origin $[1,3]$.

The skin lesion was named after Sister Mary Joseph, surgical assistant to Dr. William J. Mayo, who noted the association of an umbilical nodule and intraabdominal malignancy in 1928 [4].

It is a rare lesion with a low incidence, $1-3 \%$ of patients with abdomino-pelvic malignancy could present a SMJ nodule [5]. It can be the first manifestation of an underlying malignant tumor as shown in the case of our patient, or represent a sign of recurrence or neoplastic progression, often towards peritoneal carcinosis [6-8]. Sister Mary Joseph's nodule represents $60 \%$ of all malignant umbilical tumors (primary or secondary) and is generally associated with a poor prognosis with an average survival of 10-12 months) $[9,10]$.

Gynecological origin is the second most common etiology after digestive origin, with ovarian cancer being the most common in $34 \%$ of cases [9].

Skin metastasis in form of SMJN from ovarian carcinoma typically occurs in advanced disease with widespread peritoneal involvement, and indicates a poor prognosis. Several mechanisms for pathogenesis of cutaneous metastases have been proposed; hematogenous or lymphatic extension, direct contiguous extension of an underlying tumor, extension from the embryonic remains, or be iatrogenic with accidental implantation following surgery, and the most common mode of spread of ovarian carcinoma to the skin is retrograde, from involved proximal lymph nodes $[11,12]$.
During diagnosis, a biopsy of the umbilical nodule provides a convenient means for histological confirmation of the disease, it is important to highlight that identifying a primary site may be challenging and in some cases, not identified $[11,13]$.

The therapeutic approach is multidisciplinary and not codified. Dermatologists, gastroenterologists, surgeons, gynecologists and oncologists should be aware of such a relatively rare entity. Treatment usually involves the proper management of the primary tumor, if it has been identified with palliative care. However, a combination of chemotherapy and surgery can provide better long-term survival for ovarian cancer [11, 14].

\section{Conclusion}

Sister Marie-Joseph's nodule is rare, but characteristic. Its recognition can allow the diagnosis of an abdomino-pelvic cancer. The presence of this nodule is often associated with a poor prognosis.

\section{REFERENCES}

1. Touré PS, Tall CT, Dioussé P, Berthé A, Diop MM, Sarr MM, Diop B, Léye YM, Diop BM, Ka MM. Nodule de Sœur Marie-Josèphe révélateur de carcinomes digestif et ovarien: à propos de 4 cas. Pan African Medical Journal. 2015;22(1).

2. Majmudar B, Wiskind AK, Croft BN, Dudley AG. The Sister (Mary) Joseph nodule: its significance in gynecology. GynecolOncol. 1991 Feb;40(2):152-9.

3. Colin M. Segovis, Raymond B. Dyer. The "Sister Mary Joseph Nodule'. AbdomRadiol (2017) 42:1610-1611.

4. Sethi K, Shareef N, Bloom S. The Sister Mary Joseph nodule. British Journal of Hospital Medicine. 2018 Feb 2;79(2):C27-9.

5. Dubreuil A, Dompmartin A, Barjot P, Louvet S, Leroy D. Umbilical metastasis or Sister Mary Joseph's nodule. Int J Dermatol. 1998 Jan;37(1):713. 
6. Papalas JA, Selim MA. Metastatic vs primary malignant neoplasms affecting the umbilicus: clinicopathologic features of 77 tumors. Ann Diagn Pathol. 2011 Aug; 15(4):237-42.

7. Gabriele R, Conte M, Egidi F, Borghese M. Umbilical metastases: current viewpoint. World J Surg Oncol. 2005 Feb 21;3(1):13.

8. Chalya PL, Mabula JB, Rambau PF, Mchembe MD. Sister Mary Joseph's nodule at a University teaching hospital in northwestern Tanzania: a retrospective review of 34 cases. World journal of surgical oncology. 2013 Dec;11(1):1-6.

9. Touraud JP, Lentz N, Dutronc Y, Mercier E, Sagot P, Lambert D. Umbilical cutaneous metastasis (or Sister Mary Joseph's nodule) disclosing an ovarian adenocarcinoma GynecolObstetFertil. 2000; 28; 719-21.

10. Martina De Angeli ,MariantoniaCarosi , Enrico Vizza , Giacomo Corrado. Sister Mary Joseph's
Nodule in Endometrial Cancer: A Case Report and Review of the Literature. J Cancer Res Ther. OctDec 2019;15(6):1408-1410.

11. Poparic S, Prohic A, Kuskunovic-Vlahovljak S, Guso E, Kapetanovic A. Sister Mary Joseph nodule in an ovary adenocarcinoma. Medical Archives. 2017 Mar 1;71(2):154.

12. Matthew T Carvey, Cristina V Beiu, Robert Hage. Case of a Sister Mary Joseph's Nodule in a High Grade Serous Carcinoma. Cureus. 2018 Dec; 10(12): e3757.

13. John A. G Gibson, William R. Thompson, Sham Konamme, Sanjeet Bhattacharya. Sister Mary Joseph nodule: a diagnostic challenge. BMJ Case Rep. 2018; 2018: bcr2017223674.

14. Fatima Safini, Nora Naqos, Souha Sahraoui, Abdellatif Benider. Sister Mary Joseph's nodule: Unusual case. J Cancer Res Ther. Jan-Mar 2016;12(1):428-30. 